\title{
Kinetic Study on Surface Dissolution of Nitrogen on Liquid Steel by Isotope Exchange Technique
}

\author{
Seung-Min HAN, ${ }^{1)}$ Joo-Hyun PARK, ${ }^{2)}$ Sung-Mo JUNG, ${ }^{3)}$ Jung-Ho PARK ${ }^{4)}$ and Dong-Joon MIN ${ }^{1)}$ \\ 1) Department of Metallurgical Engineering, Yonsei University, Seoul 120-749, Korea. E-mail: chemical@yonsei.ac.kr \\ 2) School of Materials Science and Engineering, University of Ulsan, Ulsan 680-749, Korea. \\ 3) Graduate Institute of Ferrous Technology (GIFT), Pohang University of Science and Technology (POSTECH), Pohang 790- \\ 784, Korea. \\ 4) Technical Research Laboratories, POSCO, Pohang 790-785, Korea.
}

(Received on August 1, 2008; accepted on January 27, 2009)

\begin{abstract}
The kinetic study of the nitrogen dissolution into the molten steel was investigated by an isotope exchange technique. The effects of $\mathrm{O}, \mathrm{S}, \mathrm{C}, \mathrm{B}$, and $\mathrm{Mn}$ addition on surface reaction have been considered at $1873 \mathrm{~K}$. Experimental results show that the rate determining step of nitrogen dissolution into molten $\mathrm{Fe}-\mathrm{O}-\mathrm{S}$ alloys would be dissociation reaction and the rate constant on bare surface of the liquid steel $\left(k^{0}\right)$ is $3.84 \times 10^{-5}\left(\mathrm{~mol} / \mathrm{cm}^{2} \cdot \mathrm{s} \cdot \mathrm{atm}\right)$. The adsorption coefficients for oxygen, sulfur, and boron which were applied the dissociation determining model were calculated to be $K_{\mathrm{O}}=120, K_{\mathrm{S}}=65$, and $K_{\mathrm{B}}=0.9$, respectively. In case of manganese addition, the rate constant can be increased with increasing the content of manganese. It seems that rate constant of bare surface of Fe-Mn alloy should be affected by addition of manganese.
\end{abstract}

KEY WORDS: kinetics; molten steel; nitrogen; isotope exchange reaction; surface dissolution; adsorption coefficient.

\section{Introduction}

Novel alloy design concepts such as a lean alloying with light elements (boron, nitrogen, and the like) have recently been proposed to satisfy the increasing demands for the critical properties of steel products. Nitrogen particularly plays a pronounced role in enhancing the mechanical properties of steel, such as nitrogen steel. For example, boron additions produce superior ductility and toughness to that in conventional low-carbon steels partly due to the formation of BN precipitates. ${ }^{1-4)}$ Among the interstitial elements in steels, nitrogen has widely been known as one of the most difficult elements to control because it is easily absorbed into molten steel from the atmosphere during steel refining processes. ${ }^{5}$ ) Thus, great attention has been paid to preventing nitrogen dissolution from air for producing hyper-clean steels.

A surface reaction of nitrogen on liquid steel and the effect of alloying elements on the reaction kinetics have been investigated by numerous researchers. ${ }^{6-12)}$ The dissolution of nitrogen obeys the Sieverts' law with thermodynamic equilibrium. Therefore, many researchers used the Sieverts' technique for measuring the rate of absorption or desorption of nitrogen in liquid iron and its alloys. They also determined the effects of surfactive and alloying elements on these rates. However, these results of absorption or desorption rate might include a rate of surface reaction which can be divided as adsorption, dissociation, dissolution and desorption between nitrogen molecules and iron melts. In order to elucidate the mechanism of nitrogen dis- solution and the maximum rate of nitrogen removal, the rate constant of this chemical reaction should be known.

Recently, the method of isotope exchange in studies on the nitrogen dissolution rates has been used to measure only the rate of chemical reaction on the surface of molten steel. ${ }^{13,14)}$ Previous experimental results from the isotope exchange technique indicated that nitrogen dissolution was a first order reaction ${ }^{15)}$ in terms of nitrogen partial pressure and that its rates strongly depended on surface active elements such as oxygen and sulfur. ${ }^{11,13,16)}$ Glaws and Fruehan ${ }^{17-19)}$ reported the effects of $\mathrm{S}, \mathrm{Cr}$ and $\mathrm{Ni}$ on the rate of nitrogen dissolution reaction on the surface of liquid iron alloys, and Tsukihashi and Fruehan, ${ }^{20)}$ using a carbon-saturated liquid iron specimen, found the effect of some alloying elements $(\mathrm{P}, \mathrm{Pb}, \mathrm{Bi}, \mathrm{Te}$, and $\mathrm{S})$ on the rate of the nitrogen dissolution reaction.

Although extensive research has been carried out, the effects of alloying elements on the nitrogen dissolution rate into liquid steel are inconsistent. In the present study the effects of alloying elements such as oxygen, sulfur, carbon, boron, and manganese on the dissolution rate of nitrogen in the molten steel have been investigated in order to clarify the adsorption and dissolution behavior of nitrogen into liquid steel.

\section{Experimental Method}

\subsection{Rate Constant of Nitrogen Dissolution}

Fruehan and Antolin ${ }^{21)}$ reported that the nitrogen dissolution rate constant, $k_{c}$ can be determined with apparent rate 
constant $\left(k_{a}\right)$ and gas phase mass transfer coefficient of nitrogen $\left(k_{m}\right)$ as follows:

$$
\frac{1}{k_{a}}=\frac{1}{k_{c}}+\frac{R T}{k_{m}}
$$

where $R\left(82.1 \mathrm{~atm} \cdot \mathrm{cm}^{3} / \mathrm{mol} \cdot \mathrm{K}\right)$ is the gas constant, $T(\mathrm{~K})$ is the gas temperature. In present study, $k_{a}$ had been measured, $k_{m}$ could be calculated by Saito equation ${ }^{22)}$ and then $k_{c}$ can be calculated.

\subsection{Isotope Exchange Reaction ${ }^{15,23)}$}

Nitrogen dissolution reaction on the surface of liquid steel can be expressed by Eq. (2) and its reaction rate can be defined by Eq. (3) as follows:

$$
\begin{aligned}
\mathrm{N}_{2}(\mathrm{~g}) & =2 \underline{\mathrm{N}}_{\text {(in metal) }} . \\
R & =k \cdot p_{\mathrm{N}_{2}}^{m} \ldots \ldots \ldots . . .
\end{aligned}
$$

where $k$ is the rate constant of nitrogen dissolution reaction into the liquid steel and $m$ is the reaction order in terms of the nitrogen partial pressure, $p_{\mathrm{N}_{2}}$. Kobayashi et al. ${ }^{15)}$ reported the nitrogen dissolution in the liquid steel is a first order reaction, therefore $m$ can be assumed to be unity. Since there are three kinds of nitrogen gas isotopes, namely, ${ }^{28} \mathrm{~N}_{2},{ }^{29} \mathrm{~N}_{2}$ and ${ }^{30} \mathrm{~N}_{2}$, the following reactions can be considered as nitrogen dissolution reactions:

$$
\begin{gathered}
{ }^{28} \mathrm{~N}_{2} \text { (gas) }=2{ }^{14} \underline{\mathrm{N}} \ldots . . \\
{ }^{29} \mathrm{~N}_{2}(\text { gas })={ }^{14} \underline{\mathrm{N}}+{ }^{15} \underline{\mathrm{N}} . . \\
\left.{ }^{30} \mathrm{~N}_{2} \text { (gas }\right)=2{ }^{15} \underline{\mathrm{N}} \ldots . .
\end{gathered}
$$

The reaction rate constant of nitrogen dissolution on the surface of liquid steel was calculated by mass balance of ${ }^{29} \mathrm{~N}_{2}$ as follows:

$$
-\ln \frac{{ }^{29} F_{e q}-{ }^{29} F_{f}}{{ }^{29} F_{e q}-{ }^{29} F_{i}}=k \frac{A R T}{V / t}
$$

where ${ }^{29} F_{e q}$ is the equilibrium fraction of ${ }^{29} \mathrm{~N}_{2}$ species, and ${ }^{29} F_{i}$ and ${ }^{29} F_{f}$ are the fractions of ${ }^{29} \mathrm{~N}_{2}$ in the ingoing and outgoing gases, respectively. $A\left(\mathrm{~cm}^{2}\right)$ is the area of liquid steelgas interface, $V\left(\mathrm{~cm}^{3}\right)$ is the gas volume, and $t(\mathrm{~s})$ is the reaction time. If complete mixing of the gas is assumed, $V / t$ can be replaced by $\bar{V}$ which is the volumetric flow rate and the rate constant can be expressed as shown in Eq. (8).

$$
k=-\frac{\bar{V}}{A R T} \ln \left(\frac{{ }^{29} F_{e q}-{ }^{29} F_{f}}{{ }^{29} F_{e q}-{ }^{29} F_{i}}\right)
$$

\subsection{Experimental Procedure}

A high frequency induction furnace with a quartz tube (OD $50 \mathrm{~mm}$, ID $40 \mathrm{~mm}$, and length $500 \mathrm{~mm}$ ) was used for the experiments (Fig. 1). A Pt-Pt/13\%Rh thermocouple mounted below the pedestal was employed for the temperature measurements. A proportional integral differential (PID) instrument was used to control the temperature within the range of $\pm 3 \mathrm{~K}$. An $\mathrm{Al}_{2} \mathrm{O}_{3}$ crucible (OD $14.5 \mathrm{~mm}$, ID 12.5 $\mathrm{mm}$, height $40 \mathrm{~mm}$ ) was used as a melt container which was

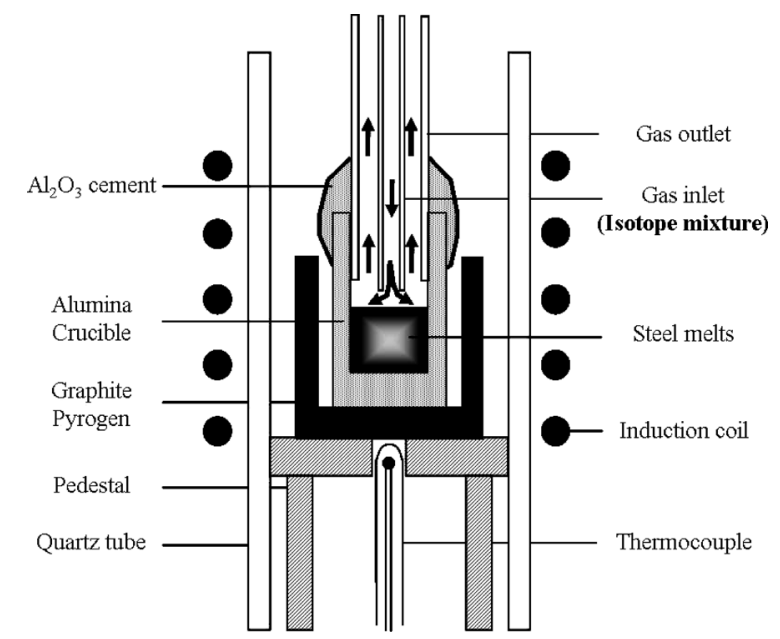

Fig. 1. Schematic diagram of experimental apparatus.

located in the graphite heater.

Several LECO $^{\circledR}$ standard steel samples (Part No. 502$348, \mathrm{O}<20 \mathrm{ppm}, \mathrm{S}<10 \mathrm{ppm}, \mathrm{C}<8 \mathrm{ppm}$, and $\mathrm{N}<3 \mathrm{ppm}$ ) were used to guarantee the uniform initial oxygen and sulfur contents in molten steel. The specimen containing carbon was prepared by mixing the carbon-saturated iron (premelted standard sample in carbon crucible at $1873 \mathrm{~K}$ ) and the standard samples. In case of the samples containing manganese or boron, an appropriate mixture of standard samples and either manganese (powder, 99\%) or boron (grinded crystalline pieces, 99.7\%) was pre-melted for target compositions in an $\mathrm{Al}_{2} \mathrm{O}_{3}$ crucible at $1873 \mathrm{~K}$. A nitrogen isotope mixture $\left(99.999 \%{ }^{28} \mathrm{~N}_{2}: 98 \%{ }^{30} \mathrm{~N}_{2}\right.$ (Cambridge Isotope Laboratories, Inc., MA, USA) in the ratio 97:3) was used to measure the dissolution rate constant. The nitrogen partial pressure was fixed in ratios from 0.4 to 0.8 by mixing nitrogen with argon $(99.9999 \%)$ gas, which was passed through magnesium chips at $723 \mathrm{~K}$. A purified argon and hydrogen $(99.9999 \%)$ gas mixture was used to remove oxygen on the surface of liquid steel for 2 min before introducing nitrogen gas mixture except for the effect of oxygen on the surface reaction rate.

An $\mathrm{Al}_{2} \mathrm{O}_{3}$ crucible containing a metal sample of about $9 \mathrm{~g}$ was put into the furnace and a dual-alumina lance for gas inlet and outlet (inner lance OD $6 \mathrm{~mm}$, ID $2 \mathrm{~mm}$, outer lance OD $12 \mathrm{~mm}$, ID $8 \mathrm{~mm}$ ) was inserted into the crucible $5 \mathrm{~mm}$ above the surface of liquid steel. The assembly was fixed immovably by alumina cement. Gas was blown at a flow rate of $500 \mathrm{~cm}^{3} \mathrm{STP} / \mathrm{min}$ through the lance. A preliminary experiment indicated those $7 \mathrm{~min}$ was required for equilibration. A quadrupole type mass spectrometer (model QUARDSTAR 422, ESS GeneSys, Cheshire, UK) was used to analyze the fraction of each gas component.

After equilibration, a crucible was quickly withdrawn from the furnace and rapidly quenched in an argon gas. The compositions of each specimen after experiment are listed in Tables 1 and 2. The contents of nitrogen and oxygen were measured by a LECO ${ }^{\circledR}$ TC-300 analyzer and those of carbon and sulfur were quantified by a LECO ${ }^{\circledR}$ CS-200 analyzer. It was confirmed that the nitrogen and sulfur contents were less than about $10 \mathrm{ppm}$, and that of oxygen was about $30 \mathrm{ppm}$. Furthermore, the manganese and boron contents in a specimen were analyzed by an atomic absorption spec- 
Table 1. Experimental results of $\mathrm{Fe}-\mathrm{O}-\mathrm{S}$ system.

\begin{tabular}{r|r|r|r|r|r}
\hline No. & mass $\%$ O & mass $\% \mathrm{~S}$ & \multicolumn{1}{c}{$\begin{array}{c}k_{\mathrm{a}} \\
\left(\mathrm{mol} / \mathrm{cm}^{2} \cdot \mathrm{s} \cdot \mathrm{atm}\right)\end{array}$} & $\begin{array}{c}k_{\mathrm{m}} / \mathrm{RT} \\
\left(\mathrm{mol} / \mathrm{cm}^{2} \cdot \mathrm{s} \cdot \mathrm{atm}\right)\end{array}$ & $\begin{array}{c}k_{\mathrm{c}} \\
\left(\mathrm{mol} / \mathrm{cm}^{2} \cdot \mathrm{s} \cdot \mathrm{atm}\right)\end{array}$ \\
\hline \hline 1 & 0.0134 & 0.0120 & $4.70 \mathrm{E}-06$ & $1.55 \mathrm{E}-04$ & $4.84 \mathrm{E}-06$ \\
2 & 0.0066 & 0.0080 & $5.70 \mathrm{E}-06$ & $1.88 \mathrm{E}-04$ & $5.88 \mathrm{E}-06$ \\
3 & 0.0066 & 0.0080 & $6.56 \mathrm{E}-06$ & $1.88 \mathrm{E}-04$ & $6.80 \mathrm{E}-06$ \\
4 & 0.0008 & 0.0008 & $2.44 \mathrm{E}-05$ & $1.93 \mathrm{E}-04$ & $2.79 \mathrm{E}-05$ \\
5 & 0.0008 & 0.0006 & $2.74 \mathrm{E}-05$ & $1.93 \mathrm{E}-04$ & $3.19 \mathrm{E}-05$ \\
6 & 0.0065 & 0.0110 & $6.42 \mathrm{E}-06$ & $1.94 \mathrm{E}-04$ & $6.64 \mathrm{E}-06$ \\
7 & 0.0424 & 0.0160 & $6.26 \mathrm{E}-07$ & $1.98 \mathrm{E}-04$ & $6.28 \mathrm{E}-07$ \\
\hline
\end{tabular}

Table 2. The composition of alloying content of specimen after experiment.

\begin{tabular}{|c|c|c|c|c|c|c|}
\hline \multicolumn{2}{|c|}{ Adding elements (\%) } & \multirow{2}{*}{$\frac{\mathrm{O}(\%)}{0.0032}$} & \multirow{2}{*}{$\frac{N(\%)}{0.0008}$} & \multirow{2}{*}{$\frac{\mathrm{C}(\%)}{0.0008}$} & \multirow{2}{*}{$\frac{\mathrm{S}(\%)}{0.0010}$} & \multirow[t]{2}{*}{$\mathrm{X}(=\mathrm{Mn}, \mathrm{B})(\%)$} \\
\hline $\mathrm{C}$ & 0.0008 & & & & & \\
\hline & 0.23 & 0.0034 & 0.0007 & 0.229 & 0.0009 & \\
\hline & 0.8 & 0.0031 & 0.0006 & 0.801 & 0.0010 & \\
\hline & 2 & 0.0033 & 0.0006 & 1.997 & 0.0009 & \\
\hline \multirow[t]{4}{*}{$\mathrm{B}$} & 0.003 & 0.0030 & 0.0006 & 0.0008 & 0.0011 & 0.0031 \\
\hline & 0.5 & 0.0030 & 0.0006 & 0.0008 & 0.0011 & 0.4897 \\
\hline & 1 & 0.0033 & 0.0005 & 0.0007 & 0.0009 & 0.978 \\
\hline & 2 & 0.0031 & 0.0004 & 0.0007 & 0.0010 & 1.986 \\
\hline \multirow[t]{6}{*}{$\mathrm{Mn}$} & 0.1 & 0.0033 & 0.0007 & 0.0009 & 0.0009 & 0.10 \\
\hline & 0.5 & 0.0032 & 0.0007 & 0.0007 & 0.0010 & 0.49 \\
\hline & 3 & 0.0034 & 0.0008 & 0.0008 & 0.0010 & 2.988 \\
\hline & 6 & 0.0032 & 0.0009 & 0.0009 & 0.0009 & 5.89 \\
\hline & 10 & 0.0034 & 0.0010 & 0.0007 & 0.0010 & 9.89 \\
\hline & 15 & 0.0033 & 0.0013 & 0.0008 & 0.0011 & 14.87 \\
\hline
\end{tabular}

trometer (model 6601-F/G, Shimadzu, Kyoto, Japan).

\section{Results and Discussion}

\subsection{Rate Determining Step for $\mathbf{F e}-\mathbf{O}-\mathrm{S}$ System}

Nitrogen dissolution into liquid steel can be described as follows:

$$
\begin{array}{ll}
\mathrm{N}_{2}(\mathrm{~g})+\square=\mathrm{N}_{2}^{\text {ad }} & \text { (Adsorption)... } \\
\mathrm{N}_{2}^{\text {ad }}+\square=2 \mathrm{~N}^{\text {ad }} & \text { (Dissociation). } \\
\mathrm{N}^{\mathrm{ad}}=\underline{\mathrm{N}}_{\text {(in Fe) }} & \text { (Dissolution).. } \\
\mathrm{N}^{\mathrm{ad}}+\mathrm{N}^{\mathrm{ad}}=\mathrm{N}_{2}^{\text {ad }}+\square & \text { (Association)... } \\
\mathrm{N}_{2}^{\text {ad }}=\mathrm{N}_{2}(\mathrm{~g})+\square & \text { (Desorption)... }
\end{array}
$$

where $\square$ refers to a vacant site on the surface of liquid steel and the superscript 'ad' denotes an adsorbed nitrogen atom or molecule on the vacant site. Generally, nitrogen gas adsorption or dissociation steps on a surface of liquid steel are known as the rate determining step of the reaction of nitrogen dissolution. Ono et ll. $^{24)}$ reported that $\mathrm{Fe}-\mathrm{O}$ system containing over the $150 \mathrm{ppm}$ of oxygen would be obedient to dissociation rate determining model and the same to the Fe-S system reported by Lee et al. ${ }^{15)}$ This can be originated from the surface active property of oxygen and sulfur and be explained by the site-blockage model. ${ }^{6,10,11,13,17,24-26)}$

If the rate determining step is considered to be the dissociation of nitrogen molecules (Eq. (9-b)), then the adsorption step (Eq. (9-a)) can be assumed in equilibrium. In this case, Eq. (3) can be expressed by Eq. (10) and satisfy Eq. (11).

$$
\begin{aligned}
& R=k_{9-b} \cdot a_{\mathrm{N}_{2}^{\mathrm{ad}}} \cdot a_{\square}=k_{9-b} \cdot K_{9-a} \cdot a_{\square}^{2} \cdot p_{\mathrm{N}_{2}} \ldots \ldots \ldots \\
& k=k_{9-b} \cdot K_{9-a} \cdot a_{\square}^{2}
\end{aligned}
$$

where $K_{9-a}$ is the equilibrium constant of Eq. (9-a), $a_{\mathrm{N}_{2}^{\text {ad }}}$ and $a_{\square}$ are the activities of adsorption site and vacant site, respectively. In an ideal case, the activity of vacant site can be denoted as $1-\sum \theta_{i}$, where $\theta_{i}$ is the fraction of adsorption sites devoted to be additive element $i$. In addition, if element $i$ exhibits Langmuir ideal adsorption behavior, then $\square+i=i^{\text {ad }}$. Accordingly, the relationship between the coverage due to adsorption of $i$ onto the surface and the activity of $i$ can be expressed by Eq. (12).

$$
\frac{\sum \theta_{i}}{1-\sum \theta_{i}}=K_{i} \cdot a_{i}
$$

where $K_{i}$ is the adsorption coefficient of additive element $i$. Therefore, the effect of additive adsorption onto the surface of liquid steel on the rate constant of nitrogen dissolution reaction can be explained by Eq. (13).

$$
k=k_{9-b} \cdot K_{9-a} \cdot\left(1-\sum \theta_{i}\right)^{2}=\frac{k_{9-b} \cdot K_{9-a}}{\left(1+\sum K_{i} \cdot f_{i}[\text { mass } \% \text { of } i]\right)^{2}}
$$

where $f_{i}$ is the Henrian activity coefficient of element $i$. In case of pure liquid iron, denominator is unity then $k\left(=k_{10-b} \cdot K_{10-a}==k^{0}\right)$ can be understood the rate of nitrogen dissolution on bare surface of liquid iron. Equation (13) indicates that the effect of additive element, $i$, on the rate of nitrogen dissolution reaction can be evaluated by its adsorption coefficient. Consequently, the adsorption coefficient will be defined by the graphical relationship between the measured rate constant and the activity of the additive element.

Figure 2 and Table 1 show the experimental results of present study in $\mathrm{Fe}-\mathrm{O}-\mathrm{S}$ system based on Eq. (13). Where, 


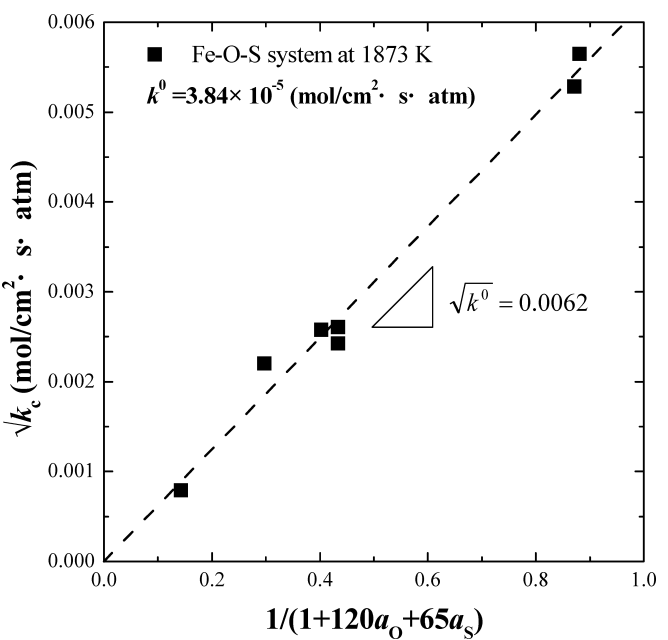

Fig. 2. Relation between $\sqrt{k_{\mathrm{c}}}$ and $1 /\left(1+120 a_{\mathrm{O}}+65 a_{\mathrm{S}}\right)$ at $1873 \mathrm{~K}$.

the adsorption coefficient of oxygen $\left(K_{\mathrm{O}}\right)$ and sulfur $\left(K_{\mathrm{S}}\right)$ could be evaluated by multiple regression analysis as 120 and 65 , respectively. Figure 2 indicates that the rate constant of nitrogen dissolution in square root has a linear relationship with $1 /\left(1+120 a_{\mathrm{O}}+65 a_{\mathrm{S}}\right)$. It means that $\mathrm{Fe}-\mathrm{O}-\mathrm{S}$ system is obedient to dissociation rate determining model. Here, the slope of straight line means the rate constant of nitrogen dissolution on bare surface of liquid steel in square root, $\sqrt{k^{0}}$ and its value was estimated as 0.0062 . Therefore, $k^{0}$ is the $3.84 \times 10^{-5}\left(\mathrm{~mol} / \mathrm{cm}^{2} \cdot \mathrm{s} \cdot \mathrm{atm}\right)$. In order to inspect this result, the rate constant on bare surface of liquid steel was shown in Fig. 3 with the temperature dependence of rate constant of nitrogen dissolution which was estimated by several authors. ${ }^{13-15,24)}$ As shown in Fig. 3, the dependence of temperature on the rate constant is different from each group according to the rate determining model. The present result is in good agreement with the Kobayashi et al.'s and Ono et al.'s data based on dissociation determining model. The other is based on adsorption determining model, which were obtained by Belton et al. ${ }^{13,14)}$ The difference of the rate constant from each other is about twice, and the activation energies also differ from $95.0 \mathrm{~kJ} / \mathrm{mol}$ (Kobayashi et al.) and $121 \mathrm{~kJ} / \mathrm{mol}$ (Byrne and Belton). According to discussion of Kobayashi et al., these discrepancies would be affected by purity of blowing gas. One of assumption, if the oxygen should be included in blowing gas, there would be possible that the nitrogen compete with oxygen for dissolution into liquid steel. However, since the competition effect of oxygen and nitrogen on the nitrogen dissolution into liquid steel has not been experimentally proved yet, further studies will be required.

\subsection{Effects of Oxygen and Sulfur in Liquid Steel on Rate Constant of Nitrogen Dissolution}

The effect of oxygen content coexisted with sulfur in the liquid steel on the rate constant of nitrogen dissolution at $1873 \mathrm{~K}$ is shown in Fig. 4 with Ono et al.'s results for $\mathrm{Fe}-\mathrm{O}$ system $\left(k^{0}=5.76 \times 10^{-5}\left(\mathrm{~mol} / \mathrm{cm}^{2} \cdot \mathrm{s} \cdot \mathrm{atm}\right), K_{\mathrm{O}}=144\right.$ at $1973 \mathrm{~K})^{24)}$ and Nagasaka's results for $\mathrm{Fe}-\mathrm{S}$ system $\left(k^{0}=5.3 \times 10^{-5}\left(\mathrm{~mol} / \mathrm{cm}^{2} \cdot \mathrm{s} \cdot \mathrm{atm}\right), K_{\mathrm{S}}=65\right.$ at $\left.\left.1873 \mathrm{~K}\right){ }^{27}\right)$ The effect of oxygen and sulfur content on the rate constant in the present experimental result can be represented by the dissociation rate determining model at $1873 \mathrm{~K}$ as follows:

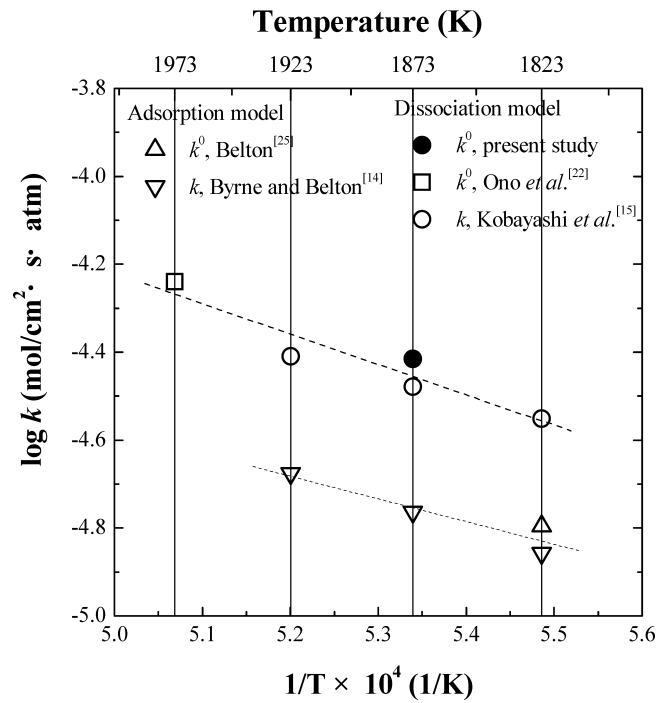

Fig. 3. The rate constant of nitrogen dissolution into liquid steel as a function of reciprocal temperature.

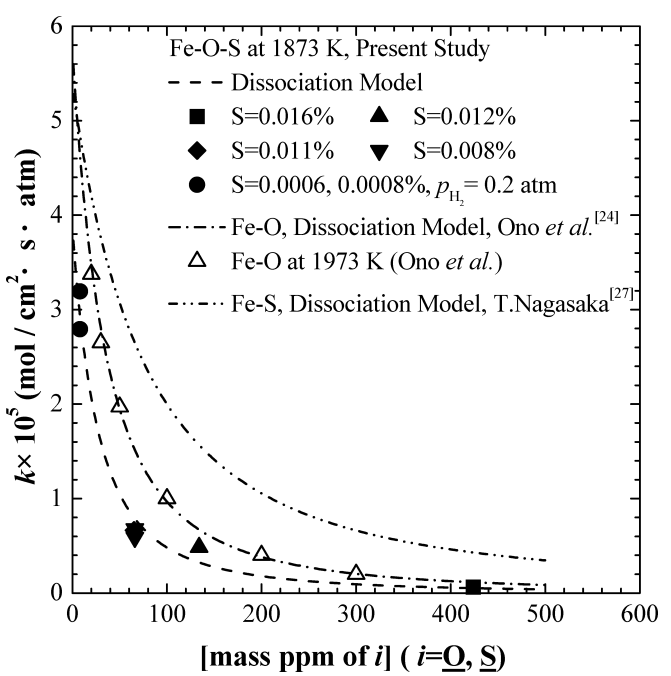

Fig. 4. Dependence of the rate constant of nitrogen dissolution on oxygen or sulfur content in liquid steel.

$$
k_{c}=\frac{3.84 \times 10^{-5}}{\left(1+120 a_{\mathrm{O}}+65 a_{\mathrm{S}}\right)^{2}}\left(\mathrm{~mol} / \mathrm{cm}^{2} \cdot \mathrm{s} \cdot \mathrm{atm}\right)
$$

As shown in Fig. 4 and Eq. (14), the rate constant of nitrogen dissolution into liquid steel dramatically decreases with increasing concentration of oxygen and sulfur and this tendency is in good agreement with the results of $\mathrm{Fe}-\mathrm{O}$ and $\mathrm{Fe}-\mathrm{S}$ system. Therefore, it is reasonable that the effect of the surfactive elements on the rate constant which was described in Eq. (12) is put together in the denominator term of the equation of rate constant such as Eq. (14).

The effect of oxygen concentration on the rate of nitrogen dissolution in liquid steel would be stronger than that of sulfur. In order to dissolve nitrogen molecule in liquid steel, two vacant sites are needed. As described in Eq. (9), nitrogen dissolution can be explained by the following sequence. First, nitrogen molecule should occupy one of vacant sites (Eq. (9-a), adsorption step). And the nitrogen molecule reacts with the neighboring vacant sites (Eq. (9-b), dissocia- 
tion step) then dissociated nitrogen atoms dissolve into the liquid steel. Because the rate of nitrogen dissolution in liquid steel is determined as the dissociation step, which is given in Eq. (13) and Fig. 2, it seems that the oxygen and sulfur atoms occupied the vacant sites required on dissociation step. The oxygen in liquid steel can play as a surface active element stronger than $\operatorname{sulfur}\left(K_{\mathrm{O}}=120>K_{\mathrm{S}}=65\right.$, present study). Therefore, if there are similar concentration of oxygen and sulfur, oxygen would be a dominant factor affecting nitrogen dissolution reaction rather than sulfur atoms.

\subsection{Effect of Carbon in Molten Steel on Rate Con- stant of Nitrogen Dissolution Reaction}

In Fig. 5, the rate constant is plotted against the activity of carbon in the liquid steel at $1873 \mathrm{~K}$ and is compared to the literature data. ${ }^{16,17,20)}$ It can be seen that the rate constant of nitrogen dissolution reaction is rarely affected by the activity of carbon, which is in good correspondence to the results measured by Fruehan et al. ${ }^{17,20)}$ However, there are slight discrepancies among the rate constant values, which could be originated from a difference in the activity of sulfur in each study. Sulfur in liquid steel is a surface active element like oxygen. Thus, sulfur content in liquid steel also has a significant influence on the effect of carbon on the rate constant. In the present study, the activity of sulfur $\left(a_{\mathrm{S}}\right)$ was about $0.001-0.003$ with respect to 1 mass $\%$ standard state at $1873 \mathrm{~K}$, whereas $a_{\mathrm{S}}$ is 0.11 and 0.25 in Fruehan et al.'s experiments, which is hundred times greater than that in the present study. Consequently, the nitrogen dissolution reaction can be described as a function of the activity of sulfur only in the $\mathrm{Fe}-\mathrm{C}-\mathrm{S}$ ternary system. It is of an interest that this is very similar to the expression of surface tension of liquid steel as reported by Kozakevitch et al. $^{28)}$

\subsection{Effect of Boron in Molten Steel on Rate Constant of Nitrogen Dissolution Reaction}

The rate constant for nitrogen dissolution is inversely proportional to boron content up to about 1 mass $\%$, and followed by a nearly constant value at $1873 \mathrm{~K}$ as shown in Fig. 6. These phenomena can be justified using the positive interaction parameter of boron with nitrogen in liquid steel alloy of $\left.0.094,{ }^{29}\right)$ which contributes to the retardation of nitrogen dissolution. The effect of boron content on the rate constant coincides with the result observed by Morita et $a l{ }^{30)}$ However, there is a discrepancy between these studies because of difference in initial oxygen content. The result by Morita et al. was determined by using molten iron containing 7-8 mass ppm oxygen.

If boron could act as a surface active element, a decrease in the rate constant of nitrogen dissolution can be explained by the adsorption coefficient. In the composition region at less than 1 mass $\%$ boron, the adsorption coefficient of boron is determined to be positive value as shown in Eq. (15).

$$
k_{c}=\frac{3.84 \times 10^{-5}}{\left(1+120 a_{\mathrm{O}}+65 a_{\mathrm{S}}+0.9 a_{\mathrm{B}}\right)^{2}}\left(\mathrm{~mol} / \mathrm{cm}^{2} \cdot \mathrm{s} \cdot \mathrm{atm}\right)
$$

In this case, it seems that boron can play as the surface

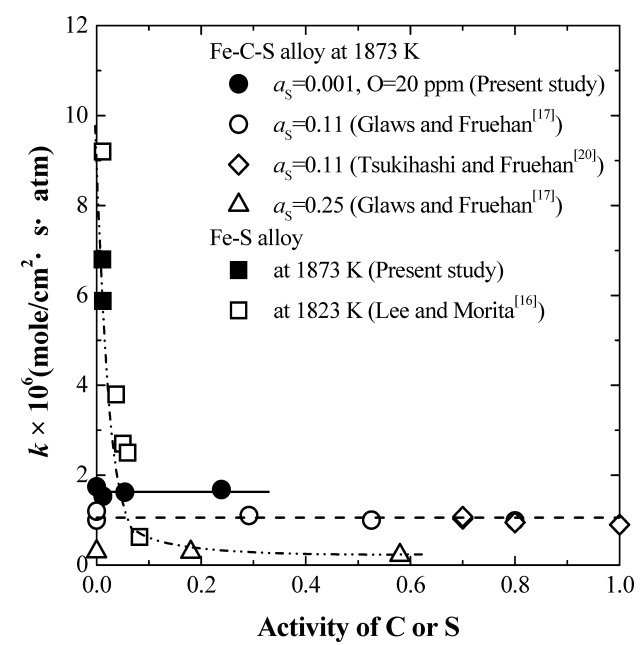

Fig. 5. Effect of activity of carbon and sulfur on the rate constant of nitrogen isotope exchange reaction.

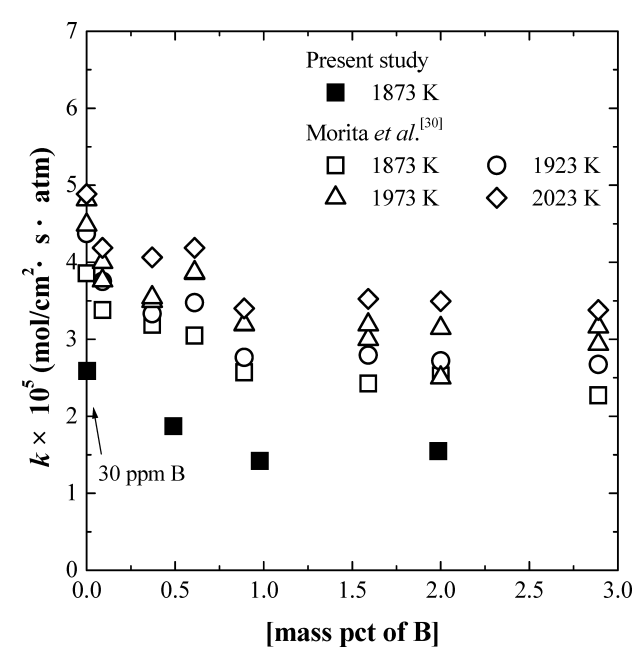

Fig. 6. Dependence of the rate constant of nitrogen isotope exchange reaction on boron content in liquid steel.

active element, even though its impact is significantly smaller than that of oxygen and sulfur.

Furthermore, a decrease in the rate constant with increasing concentration of boron in the alloys might be attributed to its small atomic size. Because the atomic radius ${ }^{31)}$ of boron $(0.85 \AA)$ is smaller than that of iron $(1.4 \AA)$, boron atoms can probably prohibit the dissolution of nitrogen by occupying the sites between iron atoms. However, since the size effect of boron on the dissolution reaction of nitrogen into liquid steel has not been experimentally proved yet, further studies will be required.

\subsection{Effect of Manganese in Molten Steel on Rate Con- stant of Nitrogen Dissolution Reaction}

Figure 7 shows the effect of manganese on the rate constant of nitrogen dissolution in molten steel. For the sake of comparison, the effects of other elements ${ }^{32,33)}$ such as vanadium, chromium, and molybdenum on the rate constant are also shown in Fig. 7. The present result of the effect of manganese on the rate constant of nitrogen dissolution is in good agreement with the results of Ono et al. Manganese and vanadium in molten steel show the acceleration effect on the nitrogen dissolution, while the effects of chromium 


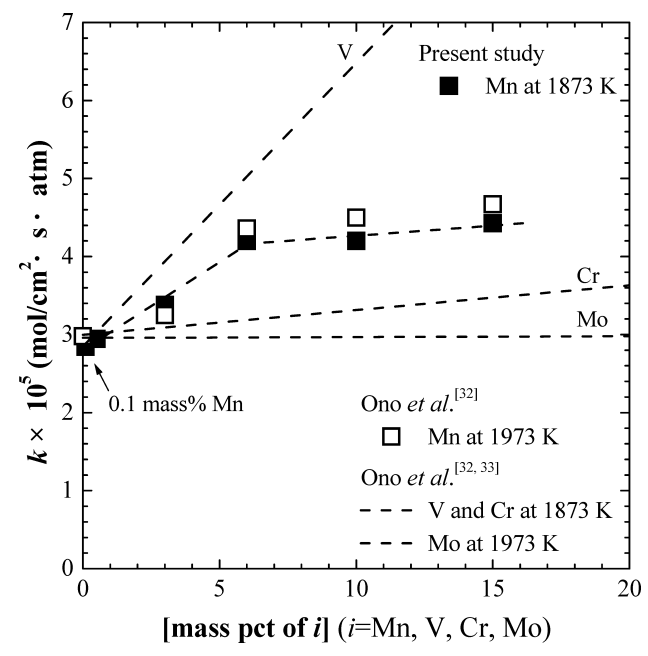

Fig. 7. Dependence of the rate constant of nitrogen isotope exchange reaction on manganese content in liquid steel.

Table 3. Interaction parameter in liquid iron alloys with nitrogen at $1873 \mathrm{~K}^{29,34)}$

\begin{tabular}{cccccccc}
\hline Elements & $\mathrm{Zr}$ & $\mathrm{V}$ & $\mathrm{Nb}$ & $\mathrm{Cr}$ & $\mathrm{Mo}$ & $\mathrm{Mn}$ & $\mathrm{T}^{31)}$ \\
\hline $\mathrm{e}_{\mathrm{N}}^{j}$ & -0.63 & -0.123 & -0.068 & -0.048 & -0.011 & -0.02 & -0.36 \\
\hline \hline Elements & $\mathrm{C}$ & $\mathrm{B}$ & $\mathrm{Si}$ & $\mathrm{Al}$ & & $\mathrm{S}$ & $\mathrm{O}$ \\
\hline $\mathrm{e}_{\mathrm{N}}^{j}$ & 0.13 & 0.094 & 0.048 & 0.01 & & 0.007 & -0.12 \\
\hline
\end{tabular}

and molybdenum are relatively small. These phenomena could be qualitatively understood based on the interaction between alloy elements and nitrogen in liquid steel as Ono et al..$^{32,33)}$ discussed (refer to Table $3^{29,34)}$ ).

As shown in Fig. 7, the rate constant is proportional to manganese content up to about 6 mass $\%$ in iron, and followed by a nearly constant value through the composition range investigated. It seems that the transition tendency of the rate constant at 6 mass $\%$ manganese in molten steel is probably caused by the change in the thermophysical property of $\mathrm{Fe}-\mathrm{Mn}$ alloy with increasing concentration of manganese. Arita and Pierre ${ }^{35)}$ reported that the kinematic viscosity $^{36)}$ and inter-diffusivity ${ }^{37)}$ in liquid $\mathrm{Fe}-\mathrm{Mn}$ alloy at $1873 \mathrm{~K}$ are changed by adding 6 mass $\%$ manganese. In addition, it can be understood by the change of excess partial molar free energy of $\mathrm{Fe}-\mathrm{Mn}$ alloy ${ }^{35)}$ due to change of liquid structure of molten $\mathrm{Fe}-\mathrm{Mn}$ alloy, which should be more developed in future works. Therefore, the rate constant of nitrogen dissolution in molten $\mathrm{Fe}-\mathrm{Mn}$ alloy could be described as follow:

$$
k_{\mathrm{Fe} \pm \mathrm{Mn}}=\frac{k_{\mathrm{Fe} \pm \mathrm{Mn}}^{0}}{\left(1+K_{\mathrm{O}}^{\mathrm{Fe} \pm \mathrm{Mn}} a_{\mathrm{O}}+K_{\mathrm{S}}^{\mathrm{Fe} \pm \mathrm{Mn}} a_{\mathrm{S}}\right)^{2}}\left(\mathrm{~mol} / \mathrm{cm}^{2} \cdot \mathrm{s} \cdot \mathrm{atm}\right)
$$

where, $k_{\mathrm{Fe}-\mathrm{Mn}}^{0}$ is the rate constant of nitrogen dissolution on the bare surface of molten $\mathrm{Fe}-\mathrm{Mn}$ alloy, and $K_{\mathrm{O}}^{\mathrm{Fe}-\mathrm{Mn}}$ and $K_{\mathrm{S}}^{\mathrm{Fe}-\mathrm{Mn}}$ are adsorption coefficient of oxygen and sulfur in molten Fe-Mn alloy, respectively.

However, the atomic radius ${ }^{31)}$ of manganese $(1.4 \AA)$ is almost same that of iron (1.4 $\AA$ ), and it form the near ideal solution in molten stee ${ }^{38)}$ which confirmed by activities behavior in the iron-manganese binary system at $1863 \mathrm{~K}^{39}{ }^{39}$ Therefore, the mole fraction of iron and manganese on the

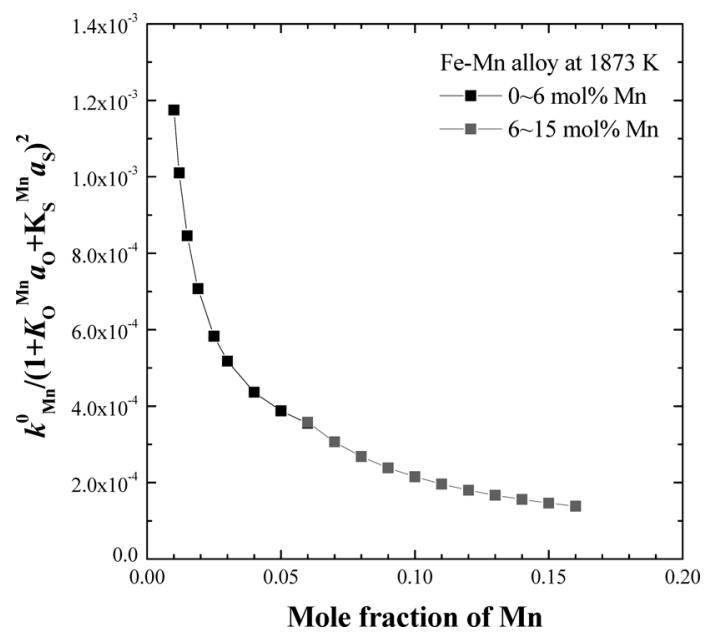

Fig. 8. Relationship between concentration of manganese and $k_{\mathrm{Mn}}^{0} /\left(1+K_{\mathrm{O}}^{\mathrm{Mn}} a_{\mathrm{O}}+K_{\mathrm{S}}^{\mathrm{Mn}} a_{\mathrm{S}}\right)^{2}$.

surface of molten Fe-Mn alloy would be expected to depend on their concentration. Moreover, the adsorption of nitrogen on molten $\mathrm{Fe}-\mathrm{Mn}$ alloy could occur independently with different interaction between nitrogen and iron or manganese atoms on surface of $\mathrm{Fe}-\mathrm{Mn}$ liquid alloy, of which was expected from different solubility of nitrogen in iron and manganese (nitrogen solubility in pure liquid iron: about $0.04 \mathrm{mass} \%$, in pure liquid $\mathrm{Mn}$ : about $1.2 \mathrm{mass} \%$ at $1873 \mathrm{~K}$ ). Tentatively assuming the modified Langmuir adsorption isotherm and considering above mentioned thermodynamic consideration, $k_{\mathrm{Fe}-\mathrm{Mn}}^{0}$ and Eq. (16) would be rearranged to (17) and (18), respectively.

$$
\begin{gathered}
k_{\mathrm{Fe} \pm \mathrm{Mn}}^{0}=k_{\mathrm{Fe}}^{0} X_{\mathrm{Fe}}+k_{\mathrm{Mn}}^{0} X_{\mathrm{Mn}} \ldots \ldots \ldots \ldots \ldots . . . \\
k_{\mathrm{Fe} \pm \mathrm{Mn}}=\frac{k_{\mathrm{Fe}}^{0} \cdot X_{\mathrm{Fe}}}{\left(1+120 a_{\mathrm{O}}+65 a_{\mathrm{S}}\right)^{2}}+\frac{k_{\mathrm{Mn}}^{0} \cdot X_{\mathrm{Mn}}}{\left(1+K_{\mathrm{O}}^{\mathrm{Mn}} a_{\mathrm{O}}+K_{\mathrm{S}}^{\mathrm{Mn}} a_{\mathrm{S}}\right)^{2}}
\end{gathered}
$$

where, $X$ is the mole fraction of iron and manganese, $k_{\mathrm{Mn}}^{0}$ is the rate constant of nitrogen on the bare surface of molten manganese, $K_{\mathrm{O}}^{\mathrm{Mn}}$ and $K_{\mathrm{S}}^{\mathrm{Mn}}$ are adsorption coefficient of oxygen and sulfur in molten manganese, respectively. Because there is no available literature data related to manganese, Eq. (18) could not been completed. However, the value of $k_{\mathrm{Mn}}^{0} /\left(1+K_{\mathrm{O}}^{\mathrm{Mn}} \cdot a_{\mathrm{O}}+K_{\mathrm{S}}^{\mathrm{Mn}} \cdot a_{\mathrm{S}}\right)^{2}$ could be estimated by using present measured data for $k_{\mathrm{Fe}-\mathrm{Mn}}$ and $k_{\mathrm{Fe}}^{0}$ as shown in Fig. 8. The value of $k_{\mathrm{Mn}}^{0} /\left(1+K_{\mathrm{O}}^{\mathrm{Mn}} \cdot a_{\mathrm{O}}+K_{\mathrm{S}}^{\mathrm{Mn}} \cdot a_{\mathrm{S}}\right)^{2}$ is approximately evaluated as 10 times as greater than the value of $k_{\mathrm{Fe}}^{0} /\left(1+120 a_{\mathrm{O}}+65 a_{\mathrm{S}}\right)^{2}$. There are two possible explanations for this complex phenomenon as follow; First, the rate constant of nitrogen dissolution on bare surface of liquid manganese, $k_{\mathrm{Mn}}^{0}$ would be higher than $k_{\mathrm{Fe}}^{0}$, because the thermodynamic interaction between nitrogen and manganese is greater than that of iron. Second, the adsorption coefficients of oxygen and sulfur in molten manganese could be smaller than that in molten iron. Because the solubility of oxygen and sulfur in manganese is larger than that in iron which can be inferred from binary phase diagrams of $\mathrm{Fe}-\mathrm{O},{ }^{38)}$ $\mathrm{Fe}-\mathrm{S},{ }^{38)} \mathrm{Mn}-\mathrm{O}^{40)}$ and $\mathrm{Mn}-\mathrm{S},{ }^{40)}$ oxygen and sulfur in bulk liquid manganese liquid would be more stable than that of 


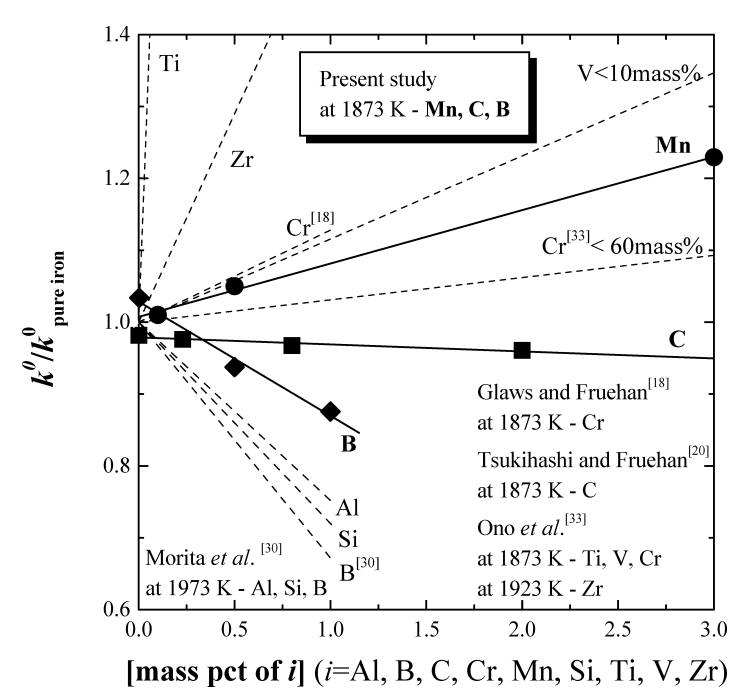

Fig. 9. Effect of content of alloying elements on the nitrogen isotope exchange reaction.

in bulk liquid iron. However, these explanations are qualitative discussion, further studies will be required.

\subsection{Comparison with the Effect of Various Elements}

In order to compare the effects of bulk concentration of carbon, manganese and boron on the nitrogen dissolution rate in the liquid steel, $k^{0} / k_{\text {pure iron }}^{0}$ ratios are plotted against their contents as shown in Fig. 9 along with the results measured by Glaws and Fruehan, ${ }^{18)}$ Tsukihashi and Fruehan, ${ }^{20)}$ Ono et al., ${ }^{33)}$ and Morita et al. ${ }^{30)}$ when the content of each additive elements is less than 1 mass\% (Here, $\mathrm{Cr}^{33}$ ) and $\mathrm{V}$ are exceptions.). The rate constant of nitrogen dissolution on the liquid steel is demonstrated as a relative value, $k_{\text {pure iron }}^{0}$ where indicates the one for pure iron. The positive slope of $k^{0} / k_{\text {pure iron }}^{0}$ indicates the positive effect of a specific element on the dissolution of nitrogen into the molten steel, whereas the negative slope represents a retardation effect. The slope of each line denotes the term $a_{\square}^{2} /[\operatorname{mass} \% i] .{ }^{33)}$

In Fig. 9, titanium, zirconium, chromium, vanadium and manganese show positive slope. This means an acceleration of nitrogen dissolution due to an increase in the activity of vacant sites on the surface of liquid steel with the addition of these elements. On the contrary, aluminum, silicon and boron play roles in retarding nitrogen dissolution. Even if these elements do not occupy the vacant sites as do surfactive elements, it seems that they could obstruct nitrogen diving into the liquid steel by decreasing the activity of vacant site. It is observed that carbon does scarcely contribute to the rate constant. These results can be qualitatively supported by considering their interaction parameters with nitrogen.

Figure 10 was constructed to compare the slopes of the lines in Fig. 9 with the interaction parameters between nitrogen and each element in the liquid steel at high temperatures. It appears that the interaction parameter has a linear relationship with the value of $a_{\square}^{2} /[\operatorname{mass} \% i]$ as given in Eq. (19). Here, Ti is excluded in least square regression.

$$
\frac{a_{\square}^{2}}{[\operatorname{mass} \% i]}=-1.03 \times e_{\mathrm{N}}^{i}-0.062\left(r^{2}=0.71\right) \cdots
$$

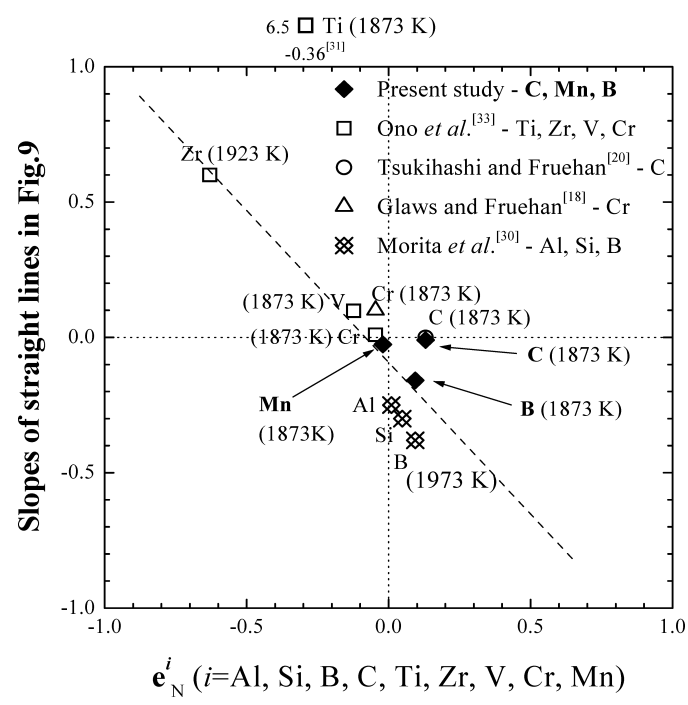

Fig. 10. Relationship between the interaction parameters of the alloying elements with nitrogen and slopes of straight lines in Fig. 9.

However, this relationship is a qualitative expression for the alloying element effects on the nitrogen dissolution reaction because the interaction parameter indicates the affinity between alloying elements and nitrogen in bulk phase. Therefore, further study will be required to clarify the interaction between nitrogen and alloying elements on the surface of the liquid steel.

\section{Summary}

The effect of alloying elements such as oxygen, sulfur, carbon, manganese, and boron on the dissolution rate of nitrogen into molten steel has been investigated in order to clarify the adsorption and dissolution behavior of nitrogen into the steel melts. The following conclusions are drawn:

(1) The rate determining step of nitrogen dissolution into $\mathrm{Fe}-\mathrm{O}-\mathrm{S}$ system is the dissociation reaction. It means that the role of surface coverage is very important.

(2) The rate constant of nitrogen isotope exchange reaction on the bare surface of the liquid steel, $k^{0}$, was estimated to be $3.84 \times 10^{-5}\left(\mathrm{~mol} / \mathrm{cm}^{2} \cdot \mathrm{s} \cdot \mathrm{atm}\right)$.

(3) The effects of surfactive elements such as oxygen and sulfur on nitrogen dissolution reaction are described by dissociation rate determining model as follow:

$$
\begin{aligned}
& k_{c}=\frac{3.84 \times 10^{-5}}{\left(1+120 a_{\mathrm{O}}+65 a_{\mathrm{S}}\right)^{2}}\left(\mathrm{~mol} / \mathrm{cm}^{2} \cdot \mathrm{s} \cdot \mathrm{atm}\right) \\
& \quad\left(K_{\mathrm{O}}=120, K_{\mathrm{S}}=65\right)
\end{aligned}
$$

(4) Boron can interrupt the nitrogen dissolution into liquid steel. It seems that the boron can be played as a weak surface active element(adsorption coefficient, $K_{\mathrm{B}}=0.9$ ) and its small atomic size could also contribute to decrease the rate constant.

(5) Manganese could accelerate the nitrogen dissolution into the liquid steel due to interaction with nitrogen stronger than iron.

\section{Acknowledgment}

The authors are grateful to Professor J. H. Lee (The 
Korea University of Seoul, Korea) for his valuable comments and discussion. And the present study was supported by POSCO, the Second Stage of Brain Korea 21 (BK21) Project of the Division of Humantronics Information Materials (The Yonsei University of Seoul, Korea) the Fundamental R\&D Program for Core Technology of Materials funded by the Ministry of Knowledge Economy, Republic of Korea.

\section{REFERENCES}

1) B. Yalamanchili, J. B. Nelson, P. M. Power and D. Lanham: Wire J. Int., 34 (2001), 90.

2) Y. R. Cho, S. I. Kim and B. S. Seong: Iron Steel Tech., 1 (2004), 46.

3) A. Wallace, A. Brownrigg, P. Hodgson and L. Frawley: Mater. Sci. Technol., 1 (2004), 275.

4) Y. Kitani, R. Ikeda, K. Yasuda, K. Oi and K. Ichimiya: Weld. World, 51 (2007), 31.

5) B. Deo and R. Boom: Fundamentals of Steelmaking Metallurgy, Prentice Hall International (UK) Limited, (1993), 246.

6) S. Ban-ya, T. Shinohara, H. Tozaki and T. Fuwa: Tetsu-to-Hagané, 60 (1974), 1443.

7) T. Choh, T. Yamada and M. Inouye: Tetsu-to-Hagané, 62 (1976), 334.

8) K. Amano, K. Ito and H. Sakao: Tetsu-to-Hagané, 62 (1976), 1179.

9) R. J. Fruehan and L. J. Martonik: Metall. Trans. B, 11B (1980), 615.

10) K. Harashima, S. Mizoguchi, H. Kajioka and K. Sakakura: Tetsu-toHagané, 73 (1987), 1559.

11) S. Ban-ya, F. Ishii, Y. Iguchi and T. Nagasaka: Metall. Trans. B, 19B (1988), 233.

12) K. Harashima, S. Mizoguchi, M. Matsuo and A. Kiyose: ISIJ Int., 32 (1992), 111.

13) G. R. Belton: Metall. Trans. B, 24B (1993), 241

14) M. Byrne and G. R. Belton: Metall. Trans. B, 14B (1983), 441

15) A. Kobayashi, F. Tsukihashi and N. Sano: ISIJ Int., 33 (1993), 1131.

16) J. Lee and K. Morita: ISIJ Int., 43 (2003), 14.

17) P. C. Glaws and R. J. Fruehan: Metall. Trans. B, 16B (1985), 551.

18) P. C. Glaws and R. J. Fruehan: Metall. Trans. B, 17B (1986), 317.

19) P. C. Glaws: The Kinetics of the Nitrogen Reaction with Liquid Iron
Alloys, Ph.D. dissertation, Carnegie-Mellon University, (1985).

20) F. Tsukihashi and R. J. Fruehan: Trans. Iron Steel Inst. Jpn., 27 (1987), 858.

21) R. J. Fruehan and S. Antolin: Metall. Trans. B, 18B (1987), 415.

22) H. Saito, A. Yoshizawa and T. Soma: Tetsu-to-Hagané, 70 (1984), 58

23) A. Ozaki: Isotopic Studies of Heterogeneous Catalysis, Kodansha Ltd. and Academic Press, Tokyo, (1977), 25.

24) H. Ono, H. Fukagawa, K. Morita and N. Sano: Metall. Trans. B, 27B (1996), 848.

25) H. Ono, K. Iuchi, K. Morita and N. Sano: ISIJ Int., 36 (1996), 1245.

26) T. Harada and D. Janke: Steel Res., 60 (1989), 337.

27) T. Nagasaka, R. J. Fruehan and A. W. Cramb: ISSTech 2003 Conf. Proc., "Ironmaking Process Technology/Wolf Symposium", Iron and Steel Society, Warrendale, PA, (2003), 979.

28) P. Kozakevitch, S. Chatel, G. Urbain and M. Sage: Rev. Metall. Cah. Inf. Tech., 52 (1955), 134.

29) The Japan Society for the Promotion of Science: The 19th Committee on Steelmaking, Steelmaking Data Sourcebook, Gordon and Breach Science Publishers, New York, (1988), 285.

30) K. Morita, T. Hirosomi and N. Sano: Metall. Trans. B, 31B (2000), 899.

31) J. C. Slater: J. Chem. Phys., 41 (1964), 3199.

32) H. Ono-Nakazato, T. Koyama and T. Usui: ISIJ Int., 43 (2003), 298.

33) H. Ono, K. Morita and N. Sano: Metall. Trans. B, 26B (1995), 991.

34) W. Y. Kim, J. O. Jo, T. I. Chung, D. S. Kim and J. J. Pak: ISIJ Int., 47 (2007), 1082.

35) M. Arita and G. S. Pierre: Tetsu-to-Hagané, 64 (1978), 206.

$36)$ B. A. Baum, Y. N. Akshentsev and P. V. Gel'd: Izv. V.U.Z. Chernaya Metall., 11 (1968), 27.

37) F. P. Calderon, N. Sano and Y. Matsushita: Metall. Trans., 2 (1971), 3325 .

38) O. Kubashcewski: IRON-Binary Phase Diagrams, Springer-Verlag, Berlin, Heidelberg, New York, (1982), 61, 80, 125.

39) J. F. Elliott, M. Gleiser and V. Ramakrishna: Thermochemistry for Steelmaking, Vol. II, Addison-Wesley Pubilshing Company, Inc., (1963), 510.

40) E. A. Brandes and G. B. Brook: Smithells Materials Reference Book, 7th ed., Butterworth-Heinemann Ltd., Oxford, (1992), 11-360, 11-364. 